\title{
Dendritic distribution of synaptic input creates a trade-off between input selectivity and flexibility
}

\author{
Michiel Remme*, Susanne Schreiber \\ From 24th Annual Computational Neuroscience Meeting: CNS*2015 \\ Prague, Czech Republic. 18-23 July 2015
}

Information processing by cortical pyramidal neurons is shaped by the spatial distribution of synapses across the dendrites. A prominent hypothesis is that synapses with similar selectivities cluster on dendritic branches. This enables cooperative interactions between neighboring synapses through activation of voltage-dependent membrane currents, and helps establish independent integrative subunits, thereby expanding the computational power of a single neuron [1]. Some recent in vivo recordings argue against this hypothesis, suggesting that inputs that share the same stimulus selectivity are randomly distributed throughout the dendritic tree (e.g., [2]). Other studies seem to support clustered configurations of input selectivities, showing for example that the activity of a synaptic input is more strongly correlated with its neighbors than with more distant inputs [3].

One fundamental feature of the nervous system that has received little attention in this ongoing discussion is learning; specifically, how is the ability to change a neuron's selectivity (i.e., its flexibility) affected by the spatial distribution of synapses? This is highly relevant because the selectivity of many cortical pyramidal neurons is subject to ongoing modification, not only during development, but throughout adulthood (e.g., [4]).

Here, we show that the distribution of synapses across active dendrites shapes both the stimulus selectivity of the neuron, as well as the flexibility of the neuron's selectivity. Using cable theoretic analysis and numerical simulations of detailed neuron models we show that synapses that are randomly distributed across the dendrites allow for a modest stimulus selectivity that can be flexibly modified through synaptic plasticity. In contrast, a clustered distribution of synapses that encode the same stimulus allows for very strong stimulus selectivity, however, it hinders adjustment of this selectivity

\footnotetext{
* Correspondence: michiel.remme@hu-berlin.de

Institute for Theoretical Biology, Humboldt University, Berlin, 10115, Germany
}

through synaptic plasticity, which requires slow and metabolically costly rearrangement of synaptic projections. Hence, the distribution of synapses across active dendrites creates a trade-off between selectivity and plasticity. We suggest that pyramidal neurons with different functions in the cortical information processing hierarchy exploit different ends of this spectrum.

\section{Acknowledgements}

This work was supported by BMBF grants no. 01GQ1001A, 01GQ0901, 01GQ0972, and the Einstein Stiftung Berlin.

Published: 18 December 2015

\section{References}

1. Larkum ME, Nevian T: Synaptic clustering by dendritic signalling mechanisms. Curr Opin Neurobiol 2008, 18(3):321-331.

2. Jia H, Rochefort NL, Chen X, Konnerth A: Dendritic organization of sensory input to cortical neurons in vivo. Nature 2010, 464:1307-1312.

3. Takahashi N et al: Locally synchronized synaptic inputs. Science 2012 , 335(6066):353-356

4. Frégnac $Y$, Shulz D, Thorpe S, Bienenstock E: A cellular analogue of visual cortical plasticity. Nature 1988, 333:367-370.

doi:10.1186/1471-2202-16-S1-P220

Cite this article as: Remme and Schreiber: Dendritic distribution of synaptic input creates a trade-off between input selectivity and flexibility. BMC Neuroscience 2015 16(Suppl 1):P220.

Submit your next manuscript to BioMed Central and take full advantage of:

- Convenient online submission

- Thorough peer review

- No space constraints or color figure charges

- Immediate publication on acceptance

- Inclusion in PubMed, CAS, Scopus and Google Scholar

- Research which is freely available for redistribution 